\title{
The Prevalence of Binge Drinking and Alcohol-Related Consequences and their Relationship among Japanese College Students
}

\author{
Kyoko Kawaida, ${ }^{1}$ Hisashi Yoshimoto,${ }^{2,3}$ Nobuaki Morita, ${ }^{1}$ Yasukazu Ogai ${ }^{1}$ and \\ Tamaki Saito ${ }^{1}$ \\ ${ }^{1}$ Social Psychiatry and Mental Health, Faculty of Medicine, University of Tsukuba, Tsukuba, Ibaraki, Japan \\ ${ }^{2}$ Department of Family Medicine, General Practice and Community Health, Faculty of Medicine, University of \\ Tsukuba, Tsukuba, Ibaraki, Japan \\ ${ }^{3}$ Kitaibaraki Center for Family Medicine, Kitaibaraki, Ibaraki, Japan
}

\begin{abstract}
Binge drinking is a common and risky behavior among college students. In Japan, however, research on the prevalence of binge drinking and alcohol-related consequences, and the relationship between them, is currently scant. The aim of this study is to examine the status of binge drinking and alcohol-related problems, and the relationship between them, among Japanese college students. We conducted a crosssectional survey of college students who participated in a health seminar or lecture including alcoholrelated contents from December 2018 to January 2019. Drinking patterns and alcohol-related consequences were assessed using the Brief Young Adult Alcohol Consequences Questionnaire (B-YAACQ) and demographic data. A total of 382 students participated in the seminar, of whom 280 agreed to cooperate in this study and 249 had drinking experience. A total of 88 men $(67.7 \%)$ and 42 women (32.2\%) were classified as binge drinkers. Binge drinkers more significantly experienced various consequences, such as hangover, feeling remorse and embarrassing behavior and some of them were suspected of physical dependence. Furthermore, logistic analysis revealed that among men, the B-YAACQ scores of binge drinkers were 2.01-fold higher those of non-binge drinkers. The findings of this study indicated that binge drinking may cause not only physical consequences but also mental and social problems, especially among men. It is important to tell college students these risks properly not to engage in binge drinking.
\end{abstract}

Keywords: alcohol-related consequences; binge drinking; Brief Young Adult Alcohol Consequences Questionnaire (B-YAACQ); college students

Tohoku J. Exp. Med., 2021 May, 254 (1), 41-47.

\section{Introduction}

The World Health Organization (WHO) reported that alcohol use resulted in an estimated 3 million deaths $(5.3 \%$ of all deaths) globally in 2016 (WHO 2018). These figures include young people, and the most recent statistics indicate that drinking by college students aged 18 to 24 contributes to an estimated 1,519 deaths per 100,000 population each year (Hingson et al. 2017). Serious alcohol-related harm includes alcohol poisoning, as well as potentially fatal injuries and accidents resulting from acute intoxication caused by excessive drinking. One excessive drinking pattern is binge drinking, which is commonly defined as the consumption of five or more standard drinks per occasion for men and four or more drinks for women (National Institute of Alcohol Abuse and Alcoholism 2004). Among full-time college students aged 18 to $22,54.9 \%$ drink alcohol and $36.9 \%$ have engaged in binge drinking in the past month (Substance Abuse and Mental Health Services Administration 2018). Furthermore, the rates of binge drinking among college students are higher than those of non-college-attending peers. In Japan, $56.8 \%$ men and $47.8 \%$ women are binge drinkers (Yoshimoto et al. 2017). Another study revealed that $74.9 \%$ of men and $59.6 \%$ of

Received March 3, 2021; revised and accepted April 1, 2021. Published online May 26, 2021; doi: 10.1620/tjem.254.41.

Correspondence: Hisashi Yoshimoto, Department of Family Medicine, General Practice and Community Health, Faculty of Medicine,

University of Tsukuba, 1-1-1 Tennoudai, Tsukuba, Ibaraki 305-8575, Japan.

e-mail: hisashiyoshi@md.tsukuba.ac.jp

(C)2021 Tohoku University Medical Press. This is an open-access article distributed under the terms of the Creative Commons Attribution-NonCommercial-NoDerivatives 4.0 International License (CC-BY-NC-ND 4.0). Anyone may download, reuse, copy, reprint, or distribute the article without modifications or adaptations for non-profit purposes if they cite the original authors and source properly.

https://creativecommons.org/licenses/by-nc-nd/4.0/ 
women have engaged in binge drinking during the past year (Kawaida et al. 2018b). These data indicate that binge drinking is common among Japanese college students.

Binge drinking has serious risks including unintentional injuries, violence, sexually transmitted disease, unintended pregnancy, chronic disease such as high blood pressure, and alcohol dependence (Correia et al. 2012; Center for Disease Control and Prevention 2014). In Japan, binge drinkers experience significantly more alcohol-related injuries [odds ratio (OR), 25.6; 95\% confidence ratio $(\mathrm{CI}), 8.05$ 81.4] (Yoshimoto et al. 2017), and it was revealed that binge drinkers significantly experience hangover than nonbinge drinkers (Kawaida et al. 2019). These results indicates that binge drinking may cause various and serious problems.

Early detection of drinking consequences may help to reduce not only their short-term impact but also long-term alcohol problems among college students. In our previous study, we used questionnaire consists of 10-item consequences focusing on physical and mental problems listed up referring previous studies. The 24-item Brief Young Adult Alcohol Consequences Questionnaire (B-YAACQ) was designed specifically to assess the severity of alcoholrelated consequences among college students (Kahler et al. 2005). Using this scale make it possible to assess alcohol consequences we did not ask in our previous study, such as self-perception, academic/occupational consequences or physical dependence. Furthermore, we can compare our results with those of previous studies.

The aim of this study was to examine the status of binge drinking and alcohol-related problems, and the relationship between them, among Japanese college students.

\section{Materials and Methods}

\section{Study design and participants}

We conducted a cross-sectional survey for college students who participated in a health seminar or lecture including alcohol-related contents from December 2018 to January 2019 at one university located in Kanto area in Japan. The anonymous self-administered questionnaire asked about drinking patterns and alcohol-related consequences using B-YAACQ and demographic data. A total of 382 students participated in the seminar, of whom 280 agreed to cooperate in this study and 249 had drinking experience. Regarding their enrolled major, 36\% $(\mathrm{n}=90)$ were health and physical education, with $16 \%(\mathrm{n}=39)$ reporting science and engineering, $11 \%(\mathrm{n}=26)$ life and environmental science, $8 \%(\mathrm{n}=21)$ humanities and culture, $7 \%(\mathrm{n}=18)$ human science, an additional 20\% $(\mathrm{n}=50)$ enrolled other major, such as social and international studies, informatics, medicine and health science and art and design, $2 \%(n=5)$ did not answer.

\section{Data collection of alcohol use}

To clarify alcohol use by college students, the Alcohol Use Disorders Identification Test-Consumption (AUDIT-C) was used to screen for alcohol use disorder (AUD). Participants were asked about the following: 1) frequency of drinking alcohol; 2) frequency of heavy episodic drinking (HED) in the past month, as evaluated by the following question: "During the past month, how often did you have six or more drinks containing any kind of alcohol on one occasion?"; 3) frequency of binge drinking in the past month, as evaluated by the following question: "During the past month, how often did you have five or more drinks (for men) or four or more drinks (for women) containing any kind of alcohol within a 2-hour period?"; 4) the maximum amount of drinking during a binge; 5) the maximum amount of drinking in the past month; and 6) normal alcohol consumption.

To ensure the accuracy of the number of drinks reported, participants were required to list everything they drank and describe the number of drinks. The questionnaire included the following types of alcohol: sake, beer, shochu (Japanese distilled alcoholic beverage), chuhai (spirit-based cocktail), cocktail, plum wine, whiskey, and wine. Regarding the frequency of drinking, each participant was asked to choose one of the following answers: "every day," "six times a week," "five times a week," "four times a week," "three times a week," "twice a week," "once a week," "three times a month," "twice a month," "once a month," "3 to 11 times a year," "once or twice a year," or "less than once a year."

The definition of one standard unit or drink differs among countries (Dawson 2011; Room and Rehm 2012; Kalinowski and Humphreys 2016). In the United States, 14 $\mathrm{g}$ of pure alcohol is considered to be a standard drink, compared with $10 \mathrm{~g}$ of pure alcohol in Japan. In this study, we used the Japanese definition of a standard drink. The definition of binge drinking varies across studies, but generally entails the consumption of five or more drinks (for men) or four or more drinks (for women) over a period of about 2 hours (National Institute of Alcohol Abuse and Alcoholism 2004). Based on the Japanese definition of a standard drink, we defined binge drinking as consumption of $50 \mathrm{~g}$ or more for men and $40 \mathrm{~g}$ or more for women in a 2-hour period in the past month.

\section{Data collection of alcohol-related consequences}

The Brief Young Adult Alcohol Consequences Questionnaire (B-YAACQ) is a 24-item scale for assessing alcohol-related problems (Dawson 2011). Participants indicated whether they had experienced any alcohol-related problem on the list in the 30 days prior to the day of assessment. This scale used a dichotomous response format (Yes/ No). Higher total scores (range $=0-24$ ) represented more negative consequences of drinking. With the permission of Kahler, who developed the B-YAACQ, we used backtranslation process based on guideline of WHO (WHO 2015).

\section{Data collection of demographic data}

Sex, age, year of study, and extracurricular activity 
were recorded for each participant.

\section{Statistical analysis}

After the distributions of age, frequency of drinking, amount of drinking during each occasion, and the frequency of binge drinking were confirmed, the t-test was used to compare normally distributed variables, and the MannWhitney U-test was used to compare binge drinkers and non-binge drinkers. The chi-squared test was used to examine differences in binge drinking experience between men and women. Also, the chi-squared test and Fisher's exact test were used to evaluate the difference in each item of the B-YAACQ between binge drinkers and non-binge drinkers. Logistic regression was conducted on binge drinking and B-YAACQ scores were adjusted for age, sex, flushing, and AUDIT-C score. Statistical significance was defined at $\mathrm{p}<$ 0.05. All statistical analyses were conducted using Stata 13.1 for Windows (Stata Corp., College Station, TX, USA).

\section{Ethical considerations}

To obtain informed consent of participants, we explained the purpose, methods, and ethical considerations of the research at the start of seminar. Submitting the questionnaire was considered as provision of informed consent. This research was approved by the medical ethics committee of the University of Tsukuba.

\section{Results}

A total of 382 students participated in health seminar, and $280(73.3 \%)$ agreed to participate in this study and 249 had $(65.1 \%)$ drinking experience (Fig. 1).

\section{Participant characteristics}

The baseline characteristics of study participants are illustrated in Table 1. The participants were 158 men $(63.4 \%)$ and 91 women $(36.6 \%)$ with a mean age of 21.1 (standard deviation [SD], 1.6). A total of 88 men (67.7\%) and 42 women $(32.2 \%)$ were classified as binge drinkers. The maximum number of drinks during binge drinking was 9.08 (SD, 3.93) for men and 7.79 (SD, 3.99) for women. Binge drinkers and non-binge drinkers differed significantly in the frequency of alcohol drinking, maximum amount of alcohol consumed per day, normal amount of drinking, AUDIT-C, flushing, and B-YAACQ score (all p < 0.001).

Difference in the prevalence of each alcohol-related consequence between binge drinkers and non-binge drinkers

Alcohol-related consequences which binge drinkers more significantly experienced were following B-YAACQ items: "I have had a hangover (headache, nausea) the morning after I had been drinking", "I have felt very sick to my stomach or thrown up after drinking", "I have felt badly about myself because of my drinking" ( $p<0.001$, respectively); "I have often found it difficult to limit how much I drink", "I have spent too much time drinking" ( $p<0.01$, respectively); "I have passed out from drinking", "While drinking, I have said or done embarrassing things" ( $p<$ 0.01 , respectively); "I have found that I needed larger amounts of alcohol to feel any effect, or that I could no longer get high or drunk on the amount that used to get me high or drunk" and "I have become very rude, obnoxious, or insulting after drinking”( $\mathrm{p}<0.05$, respectively) (Table 2).

Excluded $(\mathrm{n}=102)$

- did not submit response $(n=102)$

- never drink $(\mathrm{n}=31)$

$$
(\mathrm{n}=249)
$$

Fig. 1. Flow chart of this study. 
Table 1. Characteristics of participants.

\begin{tabular}{|c|c|c|c|c|}
\hline Variable & $\begin{array}{c}\text { Total } \\
(\mathrm{n}=249)\end{array}$ & $\begin{array}{l}\text { Binge }(+) \\
(\mathrm{n}=130)\end{array}$ & $\begin{array}{c}\text { Binge (-) } \\
(\mathrm{n}=119)\end{array}$ & $\mathrm{p}$ \\
\hline Age (years) & $21.1 \pm 1.6$ & $21.1 \pm 1.4$ & $21.2 \pm 1.8$ & $0.625^{\mathrm{b}}$ \\
\hline Frequency of drinking in a month & $5.0 \pm 5.7$ & $7.1 \pm 6.3$ & $2.6 \pm 3.6$ & $<0.001^{\mathrm{d}}$ \\
\hline Frequency of HED ${ }^{\mathrm{a}}$ in a month & $2.4 \pm 4.0$ & $4.3 \pm 4.8$ & $0.4 \pm 0.9$ & $<0.001^{\mathrm{d}}$ \\
\hline Maximum amount of drinking (drinks/day) & $7.0 \pm 5.7$ & $10.3 \pm 5.7$ & $3.4 \pm 2.6$ & $<0.001^{\mathrm{b}}$ \\
\hline Normal amount of drinking (drink/day) & $4.0 \pm 2.7$ & $5.1 \pm 2.9$ & $2.9 \pm 1.9$ & $<0.001^{\mathrm{b}}$ \\
\hline AUDIT-C & $4.3 \pm 2.3$ & $5.7 \pm 2.0$ & $2.7 \pm 1.5$ & $<0.001^{\mathrm{b}}$ \\
\hline \multicolumn{5}{|l|}{ Sex } \\
\hline Men & $158(63.4)$ & $88(67.7)$ & $70(58.8)$ & $0.147^{\mathrm{c}}$ \\
\hline Women & $91(36.6)$ & $42(32.3)$ & $49(41.2)$ & \\
\hline \multicolumn{5}{|l|}{ Flushing } \\
\hline Positive & $88(35.9)$ & $31(23.8)$ & $57(47.9)$ & $<0.001^{\mathrm{c}}$ \\
\hline Negative & $161(65.1)$ & $99(76.2)$ & $62(52.1)$ & \\
\hline B-YAACQ & $1.6 \pm 2.2$ & $2.3 \pm 2.5$ & $0.8 \pm 1.5$ & $<0.001^{\mathrm{d}}$ \\
\hline
\end{tabular}

Data are shown as mean $\pm \mathrm{SD}$ or $\mathrm{n}(\%)$.

aPure alcohol intake of $60 \mathrm{~g}$ or more on one occasion. ${ }^{\mathrm{b} I n d e p e n d e n t ~ t-t e s t ~[b i n g e ~}(+)$ vs. binge $\left.(-)\right]$. ${ }^{\mathrm{c}}$ Chi-squared test [binge $(+)$ vs. binge $(-)$ ]. dMann-Whitney [binge $(+)$ vs. binge $(-)$ ].

HED, Heavy Episodic Drinking; AUDIT-C, Alcohol Use Disorders Identification Test -Consumption; B-YAACQ, Brief Young Adult Alcohol Consequences Questionnaire.

\section{Relationship between binge drinking and B-YAACQ scores}

There was a significant difference in B-YAACQ scores between binge drinkers $(2.3 \pm 2.5)$ and non-binge drinkers $(0.8 \pm 1.5)$ (Fig. 2). Furthermore, logistic analysis revealed that among men, the B-YAACQ scores of binge drinkers were 2.01-fold higher than those of non-binge drinkers after adjusting for age, flushing, and AUDIT-C score (Table 3).

\section{Discussion}

Key results

This study confirms that there is a significant difference in B-YAACQ scores between binge and non-binge drinkers. In addition, there was a particularly significant difference not only in physical symptoms, but also in social or mental problems, between binge and non-binge drinkers. In addition, the B-YAACQ scores increased almost 2-fold $(2.3 \pm 2.5$ vs. $0.8 \pm 1.5)$ among men.

\section{Comparison with previous studies}

In our sample, the mean B-YAACQ score was 2.3 (SD, 2.5) among binge drinkers and 0.8 (SD, 1.5) among nonbinge drinkers. The score among binge drinkers was not consistent with results obtained in the United States: a B-YAACQ score of 7.1 (SD, 4.3) was observed among atrisk drinkers, defined as those with weekly consumption of 14 or more drinks for a male ( 7 or more for a female) or at least four heavy drinking episodes in the past month (Room and Rehm 2012). The same US study defined HED as consumption of five or more drinks for men or four or more drinks for women in one sitting. Although the duration of drinking used in that study differed from ours, the number of standard drinks consumed was the same. Also, the feedback period of the B-YAACQ was 30 days prior to the day of assessment in our study, and almost the same in the US study (past month). The possible explanation for the difference in B-YAACQ scores between our study (2.3) and the US study (7.1) could have been the difference in the definition of one standard drink between the two countries: a standard drink is $10 \mathrm{~g}$ of pure ethanol in Japan vs. $14 \mathrm{~g}$ in the US. Therefore, the definition of a heavy drinking episode was consumption of $70 \mathrm{~g}$ of pure ethanol or more for men or $56 \mathrm{~g}$ or more for women in one sitting in the US study, vs. $50 \mathrm{~g}$ of pure ethanol or more for men or $40 \mathrm{~g}$ or more for women in a 2-hour period in our study. We assume that greater alcohol consumption led to more problems among the participants of the US study.

Among binge drinkers, the statistically significant items of the B-YAACQ were "I have had a hangover," "I have felt very sick to my stomach," "I have felt badly about myself," "I have often found it difficult to limit how much I drink," "I have spent too much time drinking," "I have passed out from drinking," "While drinking, I have said or done embarrassing things," "I have found that I needed larger amounts of alcohol to feel any effect," and "I have become very rude, obnoxious or insulting after drinking." We assumed that binge drinkers were more likely to experience not only a number of short-term physical consequences, but also social and mental problems. Physical symptoms like hangover or vomiting were the same in our previous study (DeMartini and Carey 2012). Although short-term physical problems were transient, they may contribute to tardiness, missed classes, or unintentional accidents like injury or risky sexual behavior.

Also, problematic behavior like saying or doing embarrassing things or becoming rude may cause problems in interpersonal relationship with others, and feeling 
Table 2. The prevalence of consequences of the 24-item Brief Young Adult Alcohol Consequences Questionnaire (B-YAACQ).

\begin{tabular}{|c|c|c|c|c|}
\hline Variable & $\begin{array}{c}\text { Total } \\
(\mathrm{n}=249)\end{array}$ & $\begin{array}{l}\text { Binge }(+) \\
(\mathrm{n}=130)\end{array}$ & $\begin{array}{l}\text { Binge }(-) \\
(\mathrm{n}=119)\end{array}$ & $\mathrm{p}$ \\
\hline 2. I have had a hangover (headache, sick stomach) the morning after I had been drinking. & $66(26.5)$ & $54(41.5)$ & $12(10.1)$ & $<0.001^{\mathrm{a}}$ \\
\hline 3. I have felt very sick to my stomach or thrown up after drinking. & $71(28.5)$ & $51(39.2)$ & $20(18.6)$ & $<0.001^{\mathrm{a}}$ \\
\hline 16. I have felt badly about myself because of my drinking. & $21(8.4)$ & $19(14.6)$ & $2(1.7)$ & $<0.001^{\mathrm{b}}$ \\
\hline 13. I have often found it difficult to limit how much I drink. & $13(5.2)$ & $12(9.2)$ & $1(0.8)$ & $\mathbf{0 . 0 0 3}^{\mathrm{b}}$ \\
\hline 19. I have spent too much time drinking. & $27(10.8)$ & $21(16.2)$ & $6(5.9)$ & $0.007^{\mathrm{a}}$ \\
\hline 6. I have passed out from drinking. & $8(3.2)$ & $8(6.2)$ & $0(0.0)$ & $0.007^{\mathrm{b}}$ \\
\hline 1. While drinking, I have said or done embarrassing things. & $23(9.2)$ & $18(13.8)$ & $5(4.2)$ & $0.009^{\mathrm{a}}$ \\
\hline $\begin{array}{l}\text { 7. I have found that I needed larger amounts of alcohol to feel any effect, or that I could } \\
\text { no longer get high or drunk on the amount that used to get me high or drunk. }\end{array}$ & $10(4.0)$ & $9(6.9)$ & $1(0.8)$ & $0.020^{b}$ \\
\hline 14. I have become very rude, obnoxious or insulting after drinking. & $6(2.4)$ & $6(4.6)$ & $0(0.0)$ & $0.030^{b}$ \\
\hline 22. I have been overweight because of drinking. & $28(11.2)$ & $19(14.6)$ & $9(7.5)$ & $0.107^{\mathrm{a}}$ \\
\hline 5. I have taken foolish risks when I have been drinking. & $7(2.8)$ & $6(4.6)$ & $1(0.8)$ & $0.122^{\mathrm{b}}$ \\
\hline 15. I have woken up in an unexpected place after heavy drinking. & $4(1.5)$ & $4(3.1)$ & $0(0.0)$ & $0.123^{\mathrm{b}}$ \\
\hline 9. I've not been able to remember large stretches of time while drinking heavily. & $9(3.6)$ & $7(5.4)$ & $2(1.7)$ & $0.176^{\mathrm{b}}$ \\
\hline 4. I often have ended up drinking on nights when I had planned not to drink. & $21(8.4)$ & $14(10.8)$ & $7(5.9)$ & $0.180^{\mathrm{a}}$ \\
\hline 8. When drinking, I have done impulsive things that I regretted later. & $5(2.0)$ & $5(3.8)$ & $0(0.0)$ & $0.610^{\mathrm{b}}$ \\
\hline $\begin{array}{l}\text { 11. I have not gone to work or missed classes at school because of drinking, a hangover, } \\
\text { or illness caused by drinking. }\end{array}$ & $13(5.2)$ & $9(6.9)$ & $4(3.4)$ & $0.260^{\mathrm{b}}$ \\
\hline 17. I have had less energy or felt tired because of my drinking. & $41(16.5)$ & $24(18.5)$ & $17(14.3)$ & $0.397^{\mathrm{a}}$ \\
\hline 12. My drinking has gotten me into sexual situations I later regretted. & $2(0.8)$ & $2(1.5)$ & $0(0.0)$ & $0.499^{\mathrm{b}}$ \\
\hline 20. I have neglected my obligations to family, work, or school because of drinking. & $6(2.4)$ & $4(3.1)$ & $2(1.7)$ & $0.686^{\mathrm{b}}$ \\
\hline 23. My physical appearance has been harmed by my drinking. & $6(2.4)$ & $4(3.1)$ & $2(1.7)$ & $0.686^{\mathrm{b}}$ \\
\hline 18. The quality of my work or schoolwork has suffered because of my drinking. & $3(1.2)$ & $2(1.5)$ & $1(0.8)$ & $1.000^{\mathrm{b}}$ \\
\hline $\begin{array}{l}\text { 21. My drinking has created problems between myself and my boyfriend/girlfriend/spouse, } \\
\text { parents, or other near relatives. }\end{array}$ & $3(1.2)$ & $2(1.5)$ & $1(0.8)$ & $1.000^{\mathrm{b}}$ \\
\hline 24. I have felt like I needed a drink after I'd gotten up (that is, before breakfast). & $3(1.2)$ & $2(1.5)$ & $1(0.8)$ & $1.000^{\mathrm{b}}$ \\
\hline 10. I have driven a car when I knew I had too much to drink to drive safely. & $0(0.0)$ & $0(0.0)$ & $0(0.0)$ & \\
\hline
\end{tabular}

Data are shown as $\mathrm{n}(\%)$.

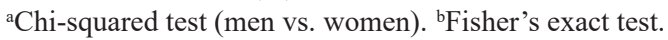

remorse for one's own drinking may negatively affect mental health. Furthermore, binge drinkers tended to need larger amounts of alcohol to feel any effect, raising the possibility of becoming alcohol-dependent. A previous study revealed that the prevalence of alcohol dependence was $10.2 \%$ among binge drinkers, vs. only $1.3 \%$ among nonbinge drinking, and a positive relationship was detected between alcohol dependence and frequency of binge drinking (Kawaida et al. 2019). It is important to identify the various risks of binge drinking and to provide the intervention appropriate for the stage of the problem.

We observed a significant difference in B-YAACQ scores between binge and non-binge drinkers only in men. Comparing the maximum number of drinks during binge drinking between men and women, men drank a bit more than women, but the difference was not significant. We assumed from this finding that men drink more rapidly than women. Due to the rapid increase in blood levels of alcohol, men experience more alcohol-related consequences than women.

\section{Implications}

This is first study to use the B-YAACQ to reveal the status of alcohol-related consequences and their relationship with binge drinking among college students in Japan. Although the B-YAACQ scores among binge drinkers was lower than in a previous foreign previous study, binge drinking clearly increased the risk of various alcoholrelated problems especially for men. Also, some students were prone to addiction. In Japan, many Japanese Izakaya restaurants provide a 2-hour nomihodai "all-you-can-drink" service, which may encourage binge drinking. In fact, using that system almost doubled the amount of drinking, as we confirmed in our previous study (Kawaida et al. 2018a). This means that students drink rapidly.

\section{Limitations}

The limitations of this study are as follows. The first is the presence of geographical bias, as the survey was performed at one university in Ibaraki Prefecture in Japan. Although this study targeted all of the students in various fields of study, more diverse sample sources and a larger 

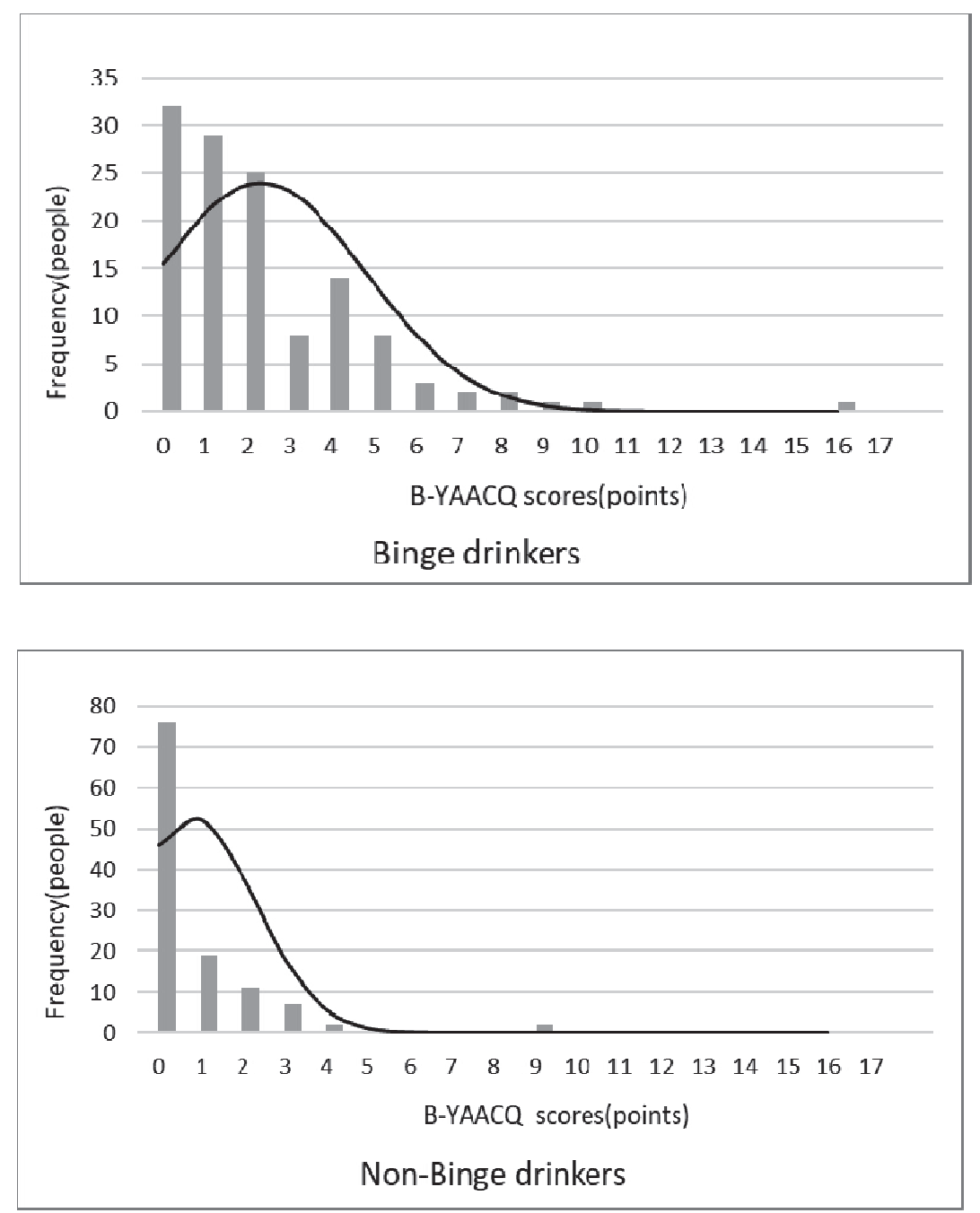

Fig. 2. Comparison of the distribution of the scores in the B-YAACQ between binge drinkers and non-binge drinkers.

Table 3. Relationship between the score of Brief Young Adult Alcohol Consequences Questionnaire (B-YAACQ) and binge drinking.

\begin{tabular}{|c|c|c|c|c|c|c|}
\hline \multirow[b]{2}{*}{ Variables } & \multicolumn{3}{|c|}{ Men } & \multicolumn{3}{|c|}{ Women } \\
\hline & $\begin{array}{l}\text { Odds } \\
\text { Ratio }\end{array}$ & $\begin{array}{c}95 \% \\
\text { Confidence } \\
\text { Interval }\end{array}$ & $\mathrm{p}$ & $\begin{array}{l}\text { Odds } \\
\text { Ratio }\end{array}$ & $\begin{array}{c}95 \% \\
\text { Confidence } \\
\text { Interval }\end{array}$ & $\mathrm{p}$ \\
\hline B-YAACQ & 2.01 & $1.37-2.95$ & $<0.001$ & 0.91 & $0.69-1.20$ & 0.53 \\
\hline Age & 1.31 & $0.83-2.10$ & 0.28 & 1.05 & $0.82-1.34$ & 0.68 \\
\hline \multicolumn{7}{|l|}{ Flushing } \\
\hline No & reference & $0.13-1.11$ & 0.08 & reference & $0.42-4.84$ & 0.57 \\
\hline Yes & 0.38 & & & 1.42 & & \\
\hline AUDIT-C & 2.89 & $1.97-4.25$ & $<0.001$ & 2.71 & $1.77-4.14$ & $<0.001$ \\
\hline
\end{tabular}

Multivariate logistic regression.

AUDIT-C, Alcohol Use Disorders Identification Test -Consumption.

sample size may be needed in future studies. The second limitation is the possible presence of recall bias. Because participants in this study reported past histories of alcohol consumption, frequency, and alcohol-related consequences using self-administered questionnaires, the actual amount of alcohol consumed and the consequences may have differed from those reported. Assessment of alcohol consumption and consequences using in-person interviews or an alcohol diary might help participants provide more thorough and accurate information. 


\section{Conclusion}

It was confirmed that binge drinking leads to various problems, such as hangover, feeling remorse and embarrassing behavior, especially among men. It is important to tell college students these risks properly not to engage in binge drinking.

\section{Conflict of Interest}

The authors declare no conflicts of interest.

\section{References}

Center for Disease Control and Prevention (2014) Facts SheetsBinge Drinking.

http://www.cdc.gov/alcohol/fact-sheets/binge-drinking.htm [Accessed: May 20, 2020].

Correia, C.J., Murphy, J.G. \& Barnett, N.P. (2012) College student alcohol abuse: A guide to assessment, intervention, and prevention. 1st ed., edited by Christopher, J.C., James, G.M. \& Nancy P.B. John Wiley \& Sons.

Dawson, D.A. (2011) Defining risk drinking. Alcohol Res. Health, 34, 144-156.

DeMartini, K.S. \& Carey, K.B. (2012) Optimizing the use of the AUDIT for alcohol screening in college students. Psychol. Assess., 24, 954-963.

Hingson, R., Zha, W. \& Smyth, D. (2017) Magnitude and trends in heavy episodic drinking, alcohol-impaired driving, and alcohol-related mortality and overdose hospitalizations among emerging adults of college ages 18-24 in the United States, 1998-2014. J. Stud. Alcohol Drugs, 78, 540-548.

Kahler, C.W., Strong, D.R. \& Read, J.P. (2005) Toward efficient and comprehensive measurement of the alcohol problems continuum in college students: the brief young adult alcohol consequences questionnaire. Alcohol. Clin. Exp. Res., 29, 1180-1189.

Kalinowski, A. \& Humphreys, K. (2016) Governmental standard drink definitions and low-risk alcohol consumption guidelines in 37 countries. Addiction, 111, 1293-1298.

Kawaida, K., Yoshimoto, H., Goto, R., Saito, G., Ogai, Y., Morita, N., \& Saito, T. (2018a) The use of all-you-can-drink system, Nomihodai, is associated with the increased alcohol consump- tion among college students: a cross-sectional study in Japan. Tohoku J. Exp. Med., 245, 263-267.

Kawaida, K., Yoshimoto, H., Goto, R., Saito, G., Ogai, Y., Morita, N., Saito, T. \& Takahashi, S. (2018b) Reasons for drinking among college students in Japan: A cross-sectional study. Tohoku J. Exp. Med., 246, 183-189.

Kawaida, K., Saito, G., Ogai, Y., Morita, N., Saito, T., Yoshimoto, H. \& Takahashi, S. (2019) Prevalence of binge drinking and association with alcohol-related consequences: a crosssectional study of college students in the Kanto region of Japan. Japanese Journal of Alcohol Atudies \& Drug Dependence, 54, 62-72.

National Institute of Alcohol Abuse and Alcoholism (2004) NIAAA council approves definition of binge drinking. https://pubs.niaaa.nih.gov/publications/Newsletter/ winter2004/Newsletter_Number3.pdf [Accessed: May 20, 2020].

Room, R. \& Rehm, J. (2012) Clear criteria based on absolute risk: reforming the basis of guidelines on low-risk drinking. Drug Alcohol Rev., 31, 135-140.

Substance Abuse and Mental Health Services Administration (SAMHSA) (2018) The National Survey on Drug Use and Health (NSDUH).

https://www.samhsa.gov/data/sites/default/files/cbhsq-reports/ Assistant-Secretary-nsduh2018_presentation.pdf [Accessed: June 20, 2020].

World Health Organization (WHO) (2015) Process of translation and adaptation of instruments. https://www.who.int/substance_abuse/research_tools/ translation/en/ [Accessed: March 1, 2021].

World Health Organization (WHO) (2018) Global status report on alcohol and health 2018. https://apps.who.int/iris/bitstream/handle/10665/274603/978 9241565639-eng.pdf?ua $=1$ [Accessed: June 20, 2020].

Yoshimoto, H., Takayashiki, A., Goto, R., Saito, G., Kawaida, K., Hieda, R., Kataoka, Y., Aramaki, M., Sakamoto, N., Maeno, T., Kobayashi, Y. \& Takemura, Y.C. (2017) Association between excessive alcohol use and alcohol-related injuries in college students: a multi-center cross-sectional study in Japan. Tohoku J. Exp. Med., 242, 157-163. 